STRUCTURAL BIOLOGY COMMUNICATIONS

ISSN 2053-230X

Received 2 April 2015

Accepted 2 April 2015

Keywords: lactoperoxidase; propylthiouracil; distal haem side; antithyroid drug; retraction

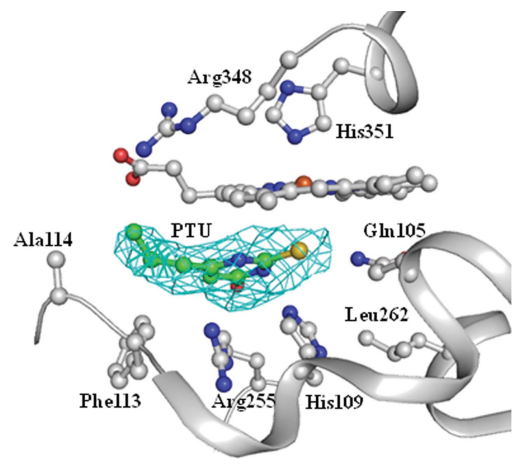

C 2015 International Union of Crystallography

\section{Mode of binding of the antithyroid drug propylthiouracil to mammalian haem peroxidases. Erratum}

\author{
R. P. Singh, A. Singh, G. S Kushwaha, A. K. Singh, P. Kaur, S. Sharma and \\ T. P. Singh*
}

Department of Biophysics, All India Institute of Medical Sciences, New Delhi, India. *Correspondence e-mail:
tpsingh.aiims@gmail.com

The results in the article by Singh et al. [(2015), Acta Cryst. F71, 304-310] have been brought into question and the article is retracted.

Concerns have been raised about the results and modelling of the ligand in the distal heme-pockets of the structure reported in the article by Singh et al. (2015). Following further investigation, the authors and Editors have agreed to retract the publication. The original PDB entry 4qyq has been obsoleted. The Editors thank the communicating author for his positive engagement, and for addressing issues raised in a timely fashion, and apologise to readers for any inconvenience.

\section{References}

Singh, R. P., Singh, A., Kushwaha, G. S., Singh, A. K., Kaur, P., Sharma, S. \& Singh, T. P. (2015). Acta Cryst. F71, 304-310. 